\title{
Role of GPCRS towards cell: an explanation of g-protein coupled receptor structure
}

\begin{abstract}
G- protein coupled receptors are the heptahelical, serpentine receptor and are multifunctional receptors having modulatory activity of a wide variety of biological process including: Neurotransmission, Chemoattraction, Cardiac function, Olfaction and Vision etc. At largest level they are involved in signal transduction across cell membranes therefore they represent major targets in the development of novel drug candidates in all clinical areas. Particularly membrane cholesterol has been reported to have a great role in the functioning of a number of GPCRs. Apart from this it also have some drawbacks. Mutations that occur are associated with a broad spectrum of diseases of diverse etiology. As a mutations result, there is a change in receptor activity (GPCR become inactive, overactive, or constitutively active), in the process of ligand binding and signal transduction. Changes in the GPCRs functioning can cause diseases such as retinitis pigmentosa (rhodopsin mutations), nephrogenic diabetes insipidus (vasopressin receptor mutations), and obesity (melanocortin receptor mutations).
\end{abstract}

Keywords: gpcrs, serpentine receptor, neurotransmission, retinitis pigmentosa, nephrogenic diabetes insipidus, bardet-biedl syndrome, hypogonadism
Volume 2 Issue 3 - 2017

\author{
Nidhi Sharma,' Anil Kumar Sahdev, ${ }^{2}$ Vinit Raj ${ }^{2}$ \\ 'Dr. K. N. Modi Institute of Pharmacy \& Research centre, \\ Modinagar, India. \\ ${ }^{2}$ Department of Pharmaceutical Sciences, Babasaheb Bhimrao \\ Ambedkar University, India
}

Correspondence: Vinit Raj, Department of Pharmaceutical Sciences, Babasaheb Bhimrao Ambedkar University, VidyaVihar, Rae Bareli Road, Lucknow-226025, Email raj.vinit24@gmail.com

Received: January 31, 2017| Published: March 27, 2017

\section{Introduction}

Every human cell is surrounded by the plasma membrane, a Phospholipid bilayer. The membrane make it possible for the cell that it can maintain a specific mixture of biochemically active species, while preventing the entry of unwanted substances from outside the environment. For proper function, the biochemical machinery in the cell needs to be able to receive the instructions from outside.

If on the outside of the cell any changes in the hormone level occurred then it elicit the adaptive changes in the enzyme activity in the inside of the cell also. Odour molecule affects cells in the olfactory epithelium and substances in the food influence chemical activities in taste buds cells, which in turn elicit electrical signals that transfer information to brain.

In human, Cells are frequently communicating with each other and with the surrounding environment also which requires a molecular framework and a proper mechanism for the transformation of information across the plasma membrane. In the body transduction of signals may takes place over long distance and it also requires a mechanism for the transformation of information over the plasma membrane.

The molecular framework means the plasma membrane which is made up of phospholipid bilayer consist of G- protein coupled receptor. The name GPCR refers to a common mode of receptor signalling via GTP- binding protein on the inside of the cells. Because their polypeptide chain passes seven times through the plasma membrane, GPCRs are also called as SEVEN- TRANSMEMBRANE $\left(7^{\mathrm{TM}}\right)$ receptor. $7^{\mathrm{TM}}$ receptors mediate the physiological signals from the outside of the cells. Then these signal can be a change in the concentration of protein, lipid, neurotransmitters, ions, hormones, odourants, tastants, etc., or an influx to the eye. GPCRs transform these signals to the inside of the cells and elicit a series of reactions involving other nucleotide, protein and metal ions, which eventually deliver a message and appropriate cellular and physiological response $^{1,2}$ (Figure 1). Receptor is a molecule on or in a cell with which a drug, hormones, neurotransmitters etc. can initially interacts. G- Protein coupled receptors are heptahelical, serpentine receptor and are multifunctional receptor having a lots of clinical implications. ${ }^{3}$

GPCRs superficially comprises the largest and most diverse group of protein in mammals and it allows the transmission of variety of signals over the cell membrane, between cells and over long distances in the body. ${ }^{4-7}$ Typically they are seven trans membrane domain protein and include $>800$ membranes which are encoded by $\sim 5 \%$ of humane genes $^{8}$ (Figure 2).

\section{Classes of GPCR}

I. Class A: Rhodopsin like
a. (Rhod)opsin
b. Olfactory
c. Prostanoid
d. Nucleotide like
e. Gonadotropine- releasing hormone
f. Thyrotropin- releasing hormone
g. Melatonin

II. Class B: Secretin like

i. Calcitonin

ii. Corticotropin releasing factor

iii. Gastric inhibitory peptide

iv. Glucagone

v. Growth hormone- realising hormone 
vi. Parathyroid hormone

vii. PACAP

viii. Secretin

ix. Vasoactive intestinal polypeptide

x. Diuretic hormone

III. Class C: Metabotropic glutamate/ pheromone

a) Metabotropic glutamate

b) Calcium sensing like

c) Putative pheromone receptor

d) GABA-B

IV. Class D: Fungal pheromone

V. Class E: cAMP receptors

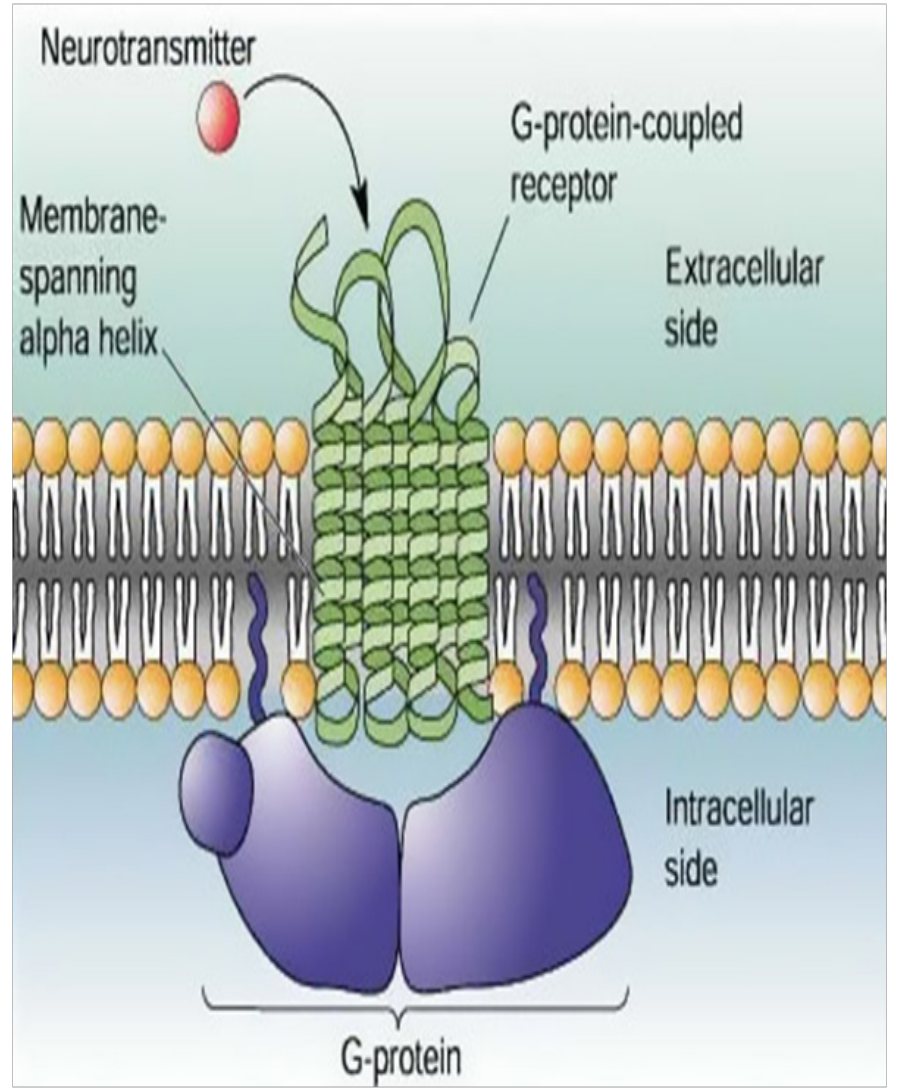

Figure I Cartoon of a section of cell in which induced GPCR in Plasma membrane (Phospholipid bilayer) is shown. The bilayer contains many proteins. The receptor is occupied by a ligand (Neurotransmitter, red in colour), bound to a G-protein (blue), and activated. The ligand does not pass through the membrane; the signal is transmitted by conformational changes in the receptor protein. ${ }^{3}$

\section{Brief introduction of ' $G$ ' Protein}

G- Protein is composed of 3 subunits alpha, beta and gaama. These G- Protein binds to the Guanosine Triphosphate (GTP) present in the receptor. Alpha and gaama subunits are linked to membrane by covalently attached lipids. The alpha subunits associate to GPCRs only when in GDP mode. G- Proteins in inactive state bound to the GDP then it moves and get bound to the GTP then after binding it gets activated. Alpha subunit of G- Protein has GTPase activity.

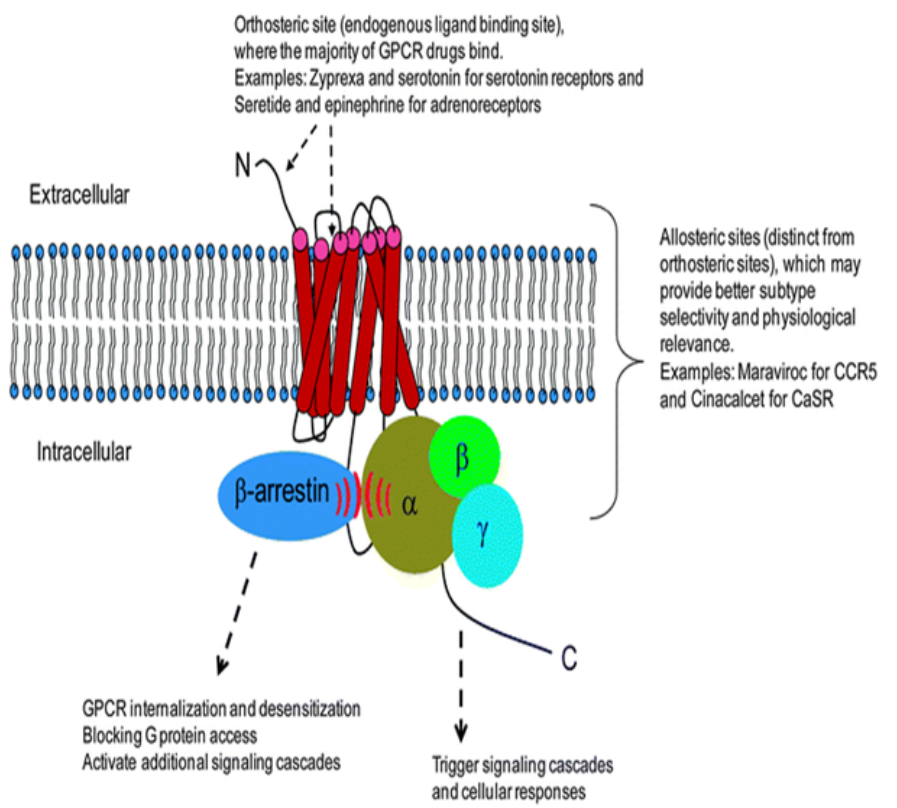

Figure 2 Outline of Mechanism of action of GPCRs. ${ }^{8}$

\section{Discovery, detection of GPCRs}

As we know that the molecular properties of $7^{\mathrm{TM}}$ receptors has been discovered over the past 40 years. However, rhodopsin had been identified as a photosensitive pigment as early as the 1870 s, and its covalent ligand retinal was reported in $1933 .{ }^{9}$ From the century ago we know about the ligand- activated receptors, in these receptors reactive cells act as a 'receptive substance' on the surface. ${ }^{10,11}$ Early experiments with tissue preparations measured the responses to stimulators (agonists) and inhibitors (antagonists). ${ }^{12}$

There are so many signalling compounds present inside the cells. These include the second messenger cyclic AMP (cAMP) and the enzyme adenylyl cyclase $\left({ }^{13}\right.$ Nobel Prize in Physiology or Medicine 1971 to Earl W. Sutherland, Jr.), cAMP-dependent protein kinase ${ }^{14}$ and heterotrimeric G-proteins, ${ }^{15-17}$ Nobel Prize in Physiology or Medicine 1994 to Martin Rodbell and Alfred G. Gilman).

The nature of the ligand-activated receptors remained controversial up to the 1970s. Epinephrine is an important hormone and neurotransmitter that influences many different physiological processes, e.g. regulation of heart rate and blood pressure. Cells responsive to epinephrine have specific plasma membrane receptors (adrenergic receptors) that interact with the hormone. There are at least nine different adrenergic receptors, grouped as $\alpha$ - and $\beta$-receptors. Different tissues and organs respond in different manners to elevated epinephrine concentration. A main goal was fulfilled when radio ligands specific for the $\beta$-receptors were found. ${ }^{18-20}$ The field exploded, and radio ligands with retained specificity were developed for a large number of receptors. Radio ligands were also used to quantify and compare the effect of a range of adrenergic compounds on the activity of $\beta$-adrenergic receptors and adenylyl cyclase. Studies of the thermodynamic coupling between ligand- and G-proteinbinding events provided insights into the signalling mechanism. ${ }^{21,22}$ 


\section{Isolation \& purification}

Isolation and purification of GPCRs in functional form in vesicles (spherical model membranes) was first achieved for rhodopsin by Ruth Hubbard. ${ }^{23}$ The receptors activation by diffusible ligands are generally found in less amount, for example: In tissues, like liver, lung and heart, and this was the reason that their isolation was very challenging. Reports on solubilized receptors for vasopressin, thyrotropin and parathyroid hormone came in $1975 . .^{24-26}$ The choice of detergent proved to be the key for the solubilization of a functional $\beta A R$ by Marc Caron and Lefkowitz. ${ }^{7,28}$ They used the same detergent as used in the earlier isolation of functional rhodopsin, ${ }^{23}$ an intriguing coincidence considering that the sequence homology between the two was unknown at the time. Affinity chromatography methods were developed to purify the receptors using specific ligands conjugated to chromatography resins. ${ }^{29,30}$ With a few additional steps, $\beta$-adrenergic receptors were purified to near theoretical specific activity. ${ }^{31-33}$

\section{Signalling mechanism}

Cell signaling is a complex system of communication, which controls and regulates basic cellular activities and coordinates cell actions. ${ }^{34}$ In biological point of view signal transduction refers to any process through which a cell converts one kind of signal into another. Signal transduction involves sequences of biochemical reactions inside the cell, which are carried out by enzymes, activated by second messengers, resulting in a signal transduction pathway.

\section{Signaling molecules}

Multicellular organisms have diverse number of small molecules and polypeptides that coordinate cell's individual biological activity.

These molecules have been functionally classified as:

Peptide hormones (e.g., Melatonin, ${ }^{35}$ Glucagon), Proteins: Growth factors (e.g., Epidermal growth factor, ${ }^{36}$ Platelet derived growth factor), Steroids (e.g., Testosterone, ${ }^{37}$ Estrogen, Progestirone, Carticosteroids), Retenoids - Synthesised from vit- A, Neurotrophins (e.g., Nerve growth factor), ${ }^{38}$ Neuropeptids (e.g., Enkephalins and Endorphins), ${ }^{39}$ Small gases (e.g., Nitric oxide), extra-cellular matrix components (e.g.,Fibronectin), ${ }^{40}$ Neurotransmittors (e.g., Acetylcholine, Dopamine, ${ }^{41}$ Adrenaline,5-HT, ${ }^{42}$ Histamine, GABA, Glutamate), Ecosanoids (e.g., Prostaglandins, Thromboxanes, Prostacyclines), Leukotrienes, Vitamines (e.g., Vit- D3), cytokines (e.g., Interferon-gamma), ${ }^{43}$ Chemokines (e.g., RANTES), ${ }^{44}$ Amino acid derivatives (e.g., epinephrine), ${ }^{44}$ Poly peptides (e.g., Insulin), ${ }^{45}$ Fatty acid derivatives.

\section{Classification of intercellular communication: cell sig- naling mechanisms-}

Intracellular signaling is subdivided into the following classes

Endocrine cell signaling: Endocrine cells secrete a polypeptide or steroid hormone into blood vessel. The hormone is then carried to a target cell, which may be located at considerable distance from the secreting cell.

Example- Estradiol is a hormone, produced by the ovary and acting on endometrium.

Paracrine cell signaling: Paracrine cells secrete hormones or growth factors that act on adjacent steroid cells.
Example-Glucagon and somatostatin acts on adjacent cells of the islets of Langernans which secrete insulin.

Autocrine cell signaling: Some hormones or growth factors such as prostaglandins and interlukins can act on the originating cell and exert an autocrine control.

Example- Autocrine signaling is found in immune cells.

Neurotransmitter cell signaling: [A specific form of paracrine signaling] in response to a neural signal, neurons secrete neurotransmitters from the axon terminals to activate adjacent neurons.

Neuro endocrine cell signaling: [A specific form of endocrine signaling] in response to a neural signal, neuroendocrine cells secret a hormone into the blood to travel to a target organ.

Example- Norepinephrine acts on hepatocytes or adipocytes.

Juxtacrine cell signaling: Signals are transmitted along cell membranes via protein or lipid components integral to the membrane and are capable of affecting either the emitting cell or cells immediately adjacent.

\section{Mechanism}

$\mathrm{G}$ protein-coupled receptor is activated by an external signal in the form of a ligand or other signal mediator. This creates a conformational change in the receptor, causing activation of a G-protein. Further effect depends on the type of $\mathrm{G}$ protein.

\section{Ligand binding}

GPCRs include receptors for sensory signal mediators (e.g., light and olfactory stimulatory molecules); adenosine, bradykinin, endothelin, melanocortins, neuropeptide $\mathrm{Y}, \gamma$ - aminobutyric acid (GABA), opioid peptides, somatostatin, hepatocyte growth factor, vasopressin, opsins, vasoactive intestinal polypeptide family, and tachykinins, chemokines; lipid mediators of inflammation (e.g., prostaglandins, prostanoids, platelet-activating factor, and leukotrienes); peptide hormones (e.g., calcitonin, follicle-stimulating hormone (FSH), gonadotropic-releasing hormone ( $\mathrm{GnRH})$, glucagon, acetylcholine (muscarinic effect), and serotonin); and biogenic amines (e.g., dopamine, epinephrine, norepinephrine, histamine, glutamate (metabotropic effect), neurokinin, thyrotropin- releasing hormone (TRH), and oxytocin).

\section{Conformational change}

It is completely known that the inactive $G$ protein is bound to the receptor in its inactive state. Once the ligand is recognized, the receptor shifts conformation and thus mechanically activates the $G$ protein, which detaches from the receptor. ${ }^{46}$ The cascade reaction on the inside of the cell starts with nucleotide exchange and the G-protein dissociates into subunits $(\mathrm{G} \alpha, \mathrm{G} \beta$ and $\mathrm{G} \gamma) \cdot{ }^{47} \mathrm{G} \alpha$ binds to and stimulates enzymes such as adelnylate cyclase. This produces the cyclic nucleotide cAMP, which diffuses easily and serves as a 'second messenger'. Other proteins may interact with $\mathrm{G} \beta$ and $\mathrm{G} \gamma$ to further modulate the signal. The activated GPCR conformation lasts long enough to allow one bound agonist molecule, or one adsorbed photon, to activate several G-proteins, which amplifies the signal. ${ }^{48,49}$ Reacted G-proteins reassociate after nucleotide hydrolysis and may re-enter the cycle.

It is known that a receptor molecule exists in a conformational 
equilibrium between active and inactive biophysical states. ${ }^{50}$ The binding of ligands to the receptor may shift the equilibrium toward the active receptor states. Three types of ligands exist: agonists are ligands which shift the equilibrium in favour of active states; inverse agonists are ligands that shift the equilibrium in favour of inactive states; and neutral antagonists are ligands that do not affect the equilibrium. It is not yet known how exactly the active and inactive states differ from each other.

\section{GPCR signaling without $\mathbf{G}$ proteins}

Some GPCRs are able to signal without $\mathrm{G}$ proteins. The ERK2 mitogen-activated protein kinase, a key signal transduction mediator downstream of receptor activation in many pathways, has been shown to be activated in response to cAMP-mediated receptor activation in the slime mold D. Discoideum despite the absence of the associated G protein $\alpha$ - and $\beta$-subunits. In mammalian cells, the much-studied $\beta_{2}$-adrenoceptor has been demonstrated to activate the ERK2 pathway after arrestin-mediated uncoupling of G-protein-mediated signaling.

In kidney cells, the bradykinin receptor $\mathrm{B}_{2}$ has been shown to interact directly with a protein tyrosine phosphatase. The presence of a tyrosine-phosphorylated ITIM (immunoreceptor tyrosine-based inhibitory motif) sequence in the $\mathrm{B}_{2}$ receptor is necessary to mediate this interaction and subsequently the antiproliferative effect of bradykinin. ${ }^{51}$

\section{Characteristics of selected GPCR in disease state}

Mutations that occur are associated with a broad spectrum of diseases of diverse etiology. As a mutations result, there is a change in receptor activity (GPCR become inactive, overactive, or constitutively active), in the process of ligand binding and signal transduction. Changes in the GPCRs functioning can cause diseases such as retinitis pigmentosa (rhodopsin mutations), nephrogenic diabetes insipidus (vasopressin receptor mutations), and obesity (melanocortin receptor mutations). Many mutational changes in genes encoding GPCR can change drug therapy of already existed diseases: heart failure (adrenergic receptors), asthma (cysteinyl leukotriene receptors). Studies concerning the structure and function of genetically modified GPCRs allow to get know a variety of mechanisms of its action, which in turn can contribute to broaden the knowledge on the etiology and pharmacotherapy of many currently incurable diseases.

Impaired signaling of various GPCRs is the cause of many congenital and acquired diseases. They are caused by number of mutations, changing the structure and function of receptors ${ }^{52}$ (Figure 3). These disorders affect GPCR activity, reinforcing the function of receptors (gain-of function) or loss (loss-offunction).

Rhodopsin is a receptor belonging to the family A (rhodopsin like receptors), which is responsible for vision process. It is located in specialized cells of the retina i.e. rod cells. All members of this family are activated by small ligands, such as biogenic amines and nucleotides, and rhodopsin is activated by photons. The action of the light is converted into an electrical signal sent to the brain. ${ }^{53}$ Rhodopsin is the first receptor of GPCRs family, for which highresolution structure was obtained by the crystallography. Rhodopsin is different from other GPCRs in that it is constantly connected with the inverse agonist 11-cis-retinal, which maintains the receptor in an inactive state. Photon absorption affects the configuration change of 11-cis-retinal to trans-retinal, and thus the conversion of rhodopsin to its active form metarhodopsin II. Consequently, transducin (G protein) coupled with rhodopsin is activated by the exchange of GDP to GTP in $\alpha$ subunit and then initiates a phototransduction cascade. ${ }^{54,55}$

Rhodopsin mutations lead to diseases associated with impaired vision. Twenty percent of them are point mutations that cause improper folding, transport or processing of the receptor. ${ }^{56}$ Mutations that cause the diseases are often nonsense mutations that lead to a single amino acid substitution in the peptide chain of the receptor. Taking into account the effects of mutations on rhodopsin receptor activity, they can be divided into two groups: a) mutations leading to an increase of receptor activity by creating constitutively active mutants (CAM). These mutant receptors are still capable of activation, even in the absence of exposure to the ligand; b) mutations leading to decreased receptor activity due to changes taking place in the phosphorylation process. The consequence of the most of these mutations is the development of the disease. Most of the known rhodopsin mutations are constitutively active rhodopsin mutants. CAM has modified binding site of an inverse agonist, 11-cis-retinal, and therefore mutated receptor is not inhibited. As a result, there is a dysfunction of rods, resulting in impairment of perception of light in the dark. Constitutively active mutants were first discovered in a severe, progressive disease that is retinitis pigmentosa (RP). ${ }^{57}$

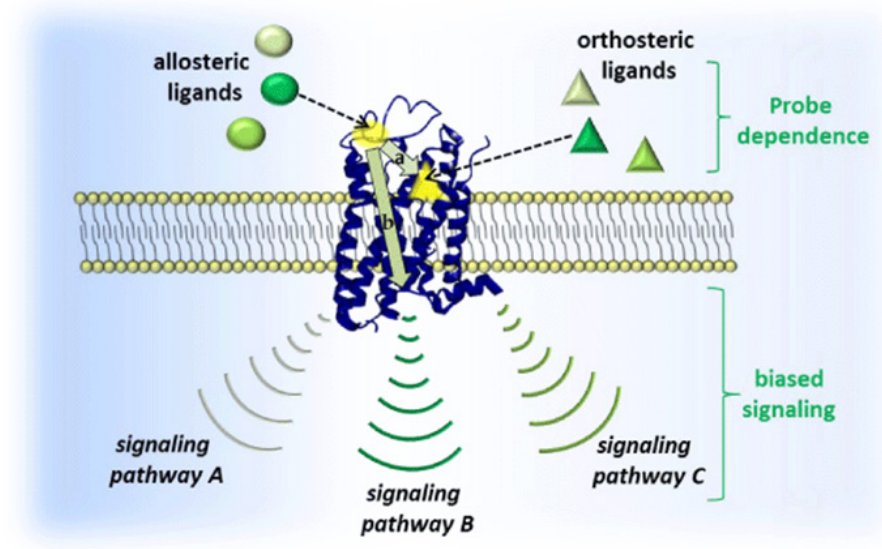

Figure 3 This picture showing the signalling pathway. ${ }^{54}$

RP defines a group of heterogeneous inherited disorders associated with changes and loss of retinal cells. RP is reported to be approximately 1:4000 people. ${ }^{58}$ Mutations in the gene encoding rhodopsin, leading to the formation of CAM, are in positions: Thr4Lys, Asn15Ser, Thr17Met, Pro23His, Pro23Leu, Gln28His, Glu113Gln and Lys296Glu. ${ }^{59}$ Classic RP begins with the problems in adaptation to the dark vision that during adolescence goes into night blindness (nyctalopia). The next stage of the disease is the progressive loss of peripheral vision in the early years of adulthood. As the disease progresses, there is a total loss of the peripheral vision with the possibility of occurrence of a tunnel vision, and usually to 60 years of age there is a loss of central vision. The symptoms are the result of progressive retinal dystrophies with reduction of two types of photoreceptors: rod cell, which enable vision in black and white in low light intensity; cone cells, which are responsible for color vision. Degeneration of both types of photoreceptors occurs in the process of apoptosis. RP is a disease damaging the visual perception, but there are cases in which the disease is associated with other disorders.

There are about 30 syndromes co-existing with RP. These include: ${ }^{58}$

Usher syndrome and RP is associated with loss of hearing. There 
are 3 types of this syndrome. In the first one, hearing loss can be very large and it manifests at birth. Balance difficulties can also occur. In the second type of disease, hearing loss can be moderate or mild and does not increase in time. At last, the third type, hearing loss occurs gradually during adolescence. Usher syndrome is a result of mutations in at least 11 genes.

Bardet-Biedl syndrome and RP is associated with other disorders such as obesity, hypogonadism, renal failure, or mental retardation. Ten genes have been identified whose mutations are responsible for $70 \%$ of RP cases. Currently, there are no drugs for selective RP pharmacotherapy. There are many different methods to prevent the progressive loss of vision. These are vitamins A and E supplementation $\tilde{n}$ the daily dose of $4.5 \mathrm{mg}$ of retinyl palmitate may delay blindness by up to 10 years; ñ docosahexaenoic acid supplementation, which belongs to the group of $\omega-3$ acids. In the membranes in which rhodopsin is located, there is significant amount of docosahexaenoic acid, an oxygen therapy ñ in normal conditions, retinal photoreceptors have high oxygen consumption. It is assumed that the supply of oxygen to the retina, can partially rescue photoreceptors and they are able to carry out the necessary metabolic processes. ${ }^{59}$

\section{Regulation of GPCRs}

There must be mechanisms for the deactivation and regulation of the signal from an active GPCR, or the signal becomes permanent. The signal can be interrupted by dissociation of the agonist, but it can also be terminated or down regulated through biochemical regulation of the receptor. Exposure to ligand may lead to down regulation. ${ }^{60}$ Phosphorylation of the intracellular part makes the receptor less sensitive to the ligand concentration ${ }^{61}$ or light; ${ }^{62}$ in other words, the receptor becomes desensitized. Specific enzymes conduct this chemical modification, for example, the $\beta$-adrenergic receptor kinases ${ }^{63}$ and rhodopsin kinase. ${ }^{64}$ Phosphorylation increases the affinity of the receptor for regulatory proteins called arrestins, ${ }^{65,66}$ leading to further down regulation. Kobilka found that internalization via endocytosis and recycling of receptors are other mechanisms for regulation of receptor signalling. ${ }^{67-69}$

\section{Conclusion}

The result concluded that a large enough panel of GPCRs has been found and systematically characterized. In addition, the nature of GPCR ligand-binding sites is greatest considered by a arrangement of site-directed mutagenesis, screening of big numbers of potential ligands and molecular modelling of the receptors. In this article, to understand what is known concerning the mechanism and structure of activation of GPCRs site primarily on two model systems.

\section{Acknowledgements}

The authors would like to express their gratitude to Babasaheb Bhimrao Ambedkar University, Lucknow, for providing the searching data facility.

\section{Conflict of interest}

The author declares no conflict of interest.

\section{References}

1. Takeda S, Kadowaki S, Haga T, et al. Identification of G protein-coupled receptor genes from the human genome sequence. FEBS Lett. 2002;520(1-3):97-101.
2. Fredriksson R, Lagerström MC, Lundin LG, et al. The G-protein-coupled receptors in the human genome form five main families. Phylogenetic Analysis, Paralogon Groups, and Fingerprints. Mol Pharmacol. 2003;63(6):1256-1272.

3. Anil M, Venu T, Gottemukkala JR, et al. Cell signaling: Role of GPCR. Coden (USA) AASRC9. 2010;2(5):363-377.

4. Pierce KL, Premont RT, Lefkowitz RJ. Seven trans membrane receptors. Nat Rev Mol Cell Biol. 2002;3(9):639-650.

5. Perez DM. The evolutionarily triumphant G-protein-coupled receptor. Mol Pharmacol. 2003;63(6):1202-1205.

6. Rosenbaum DM, Rasmussen SG, Kobilka BK. The structure and function of G-protein-coupled receptors. Nature. 2009;45(7245):356-363.

7. Venkatakrishnan AJ, Deupi X, Lebon G, et al. Molecular signatures of Gprotein-coupled receptors. Nature. 2013;494(7436):185-194.

8. Zhang Y, Devries ME, Skolnick J. Structure modelling of all identified G protein-coupled receptors in the human genome. PLoS Comput Biol. 2006;2(2):e13.

9. Fredriksson R, Lagerström MC, Lundin LG, et al. The G-protein-coupled receptors in the human genome form five main families. Phylogenetic Analysis, Paralogon Groups, and Fingerprints. Mol Pharmacol. 2003;63(6):1256-1272.

10. Krishnan A, Almén MS, Fredriksson R, et al. The origin of GPCRs: identification of mammalian like Rhodopsin, Adhesion, Glutamate and Frizzled GPCRs in fungi. PLoS One. 2012;7(1):e29817.

11. Wald G. Vitamin A in the retina. Nature. 1933;132:316-317.

12. Langley JN. Observation on the physiological action of extracts of the supra-renal bodies. J Physiol. 1901;27(3):231-256.

13. Dale HH. On some physiological actions of ergot. $J$ Physiol. 1906;34(3):163-206.

14. Furchgott RF. Receptor mechanisms. Annu Rev Pharmacol. 1964;4:2150 .

15. Rall TW, Sutherland EW. Formation of a cyclic adenine ribonucleotide by tissue particles. J Biol Chem. 1958;232(2):1065-1076.

16. Walsh DA, Perkins JP, Krebs EG. An adenosine 3',5'-monophosphate-dependent protein kinase from rabbit skeletal muscle. $J$ Biol Chem. 1968;243(13):3763-3765.

17. Rodbell M, Birmbaumer L, Posh SL, et al. The glucagon-sensitive adenylyl-cyclase system in plasma membranes of rat liver. V. An obligatory role of guanyl-nucleotides in glucagon action. J Biol Chem. 1971;246(6):1877-1882.

18. Ross EM, Gilman AG. Resolution of some components of adenylate cyclase necessary for catalytic activity. J Biol Chem. 1977;252(20):69666969.

19. Gilman AG. G proteins: transducers of receptor-generated signals. Annu Rev Biochem. 1987;56:615-649.

20. Levitzki A, Atlas D, Steer ML. The binding characteristics and number of beta-adrenergic receptors on the turkey erythrocyte. Proc Natl Acad Sci USA. 1974;71(7):2773-2776.

21. Lefkowitz RJ, Mukherjee C, Coverstone M, et al. Stereospecific $(3 \mathrm{H})$ (minus)-alprenolol binding sites, beta-adrenergic receptors and adenylate cyclase. Biochem Biophys Res Commun. 1974;60(2):703-709.

22. Aurbach GD. Beta-adrenergic receptor: strereospecific interaction of iodinated beta-blocking agent with high affinity site. Science. 1974;186(4170):1223-1224. 
23. De Lean A, Stadel JM, Lefkowitz RL. A ternary complex model explains the agonist-specific binding properties and the adenylate cyclase-coupled beta-adrenergic receptor. J Biol Chem. 1980;255(15):7108-7117.

24. Limbird LE, Gill DM, Lefkowitz RL. Agonist-promoted coupling of the beta-adrenergic receptor with the guanine nucleotide regulatory protein of the adenylate cyclase system. Proc Natl Acad Sci USA 1980;77(2):775-779.

25. Hubbard R. The molecular weight of rhodopsin and nature of the rhodopsin-digitonin complex. J Gen Physiol. 1954;37(3):381-399.

26. Tate RL, Schwartz HI, Holmes JM, et al. Thyrotropin receptors in thyroid plasma membranes. Characteristics of thyrotropin binding and solubilization of thyrotropin receptor activity by tryptic dihestion. J Biol Chem. 1975;250:6509-6515.

27. Roy C, Rajerison R, Bockaert J, et al. Solubilization of the [8-lysine] vasopressin receptor and adenylate cyclase from pig kidney plasma membrane. J Biol Chem. 1975;250(19):7885-7893.

28. Malbon CC, Zull JE. Solubilization of parathyroid hormone receptor from bovine kidney cortex plasma membranes. Biochem Biophys Res Commun. 1975;66(1):179-187.

29. Caron MG, Lefkowitz RJ. Beta-adrenergic receptors: solubilization of $(-)(3 \mathrm{H})$ alprenolol binding sites from frog erythrocyte membranes. Biochem Biophys Res Commun. 1976;68(2):315-322.

30. Caron MG, Lefkowitz RJ. Solubilization and characterization of betaadrenergic receptors binding sites from frog erythrocytes. J Biol Chem 1976;251(8):2374-2384

31. Vauquelin G, Geynert P, Hanoune J, et al. Isolation of adenylate cyclasefree, beta-adrenergic receptor from turkey erythrocyte membranes by affinity chromatography. Proc Natl Acad Sci USA. 1977;74(9):3710-3714.

32. Ross EM, Gilman AG. Biochemical properties of hormone-sensitive adenylate cyclase. Anпu Rev Biochem. 1980;49:533-564.

33. Fung B Stryer L. Photolyzed rhodopsin catalyses the exchange of GTP for bound GDP in retinal rod outer segments. Proc Natl Acad Sci USA 1980;77(5):2500-2504.

34. Pedersen SE, Ross EM. Functional reconstitution of beta-adrenergic receptors and the stimulatory GTP-binding protein of adelnylate cyclase. Proc Natl Acad Sci USA. 1982;79(23):7228-7232.

35. Mukherjee C, Caron MG, Lefkowitz RJ. Catecholamine-induced subsensitivity of adelnylate cyclase associated with loss of beta-adrenergic receptor binding sites. Proc Natl Acad Sci USA. 1975;72(5):1945-1949.

36. Stadel JM, Nambi P, Shorr RG, et al. Catecholamine-induced desensitiziation of turkey erythrocyte adenylate cyclase is associated with phosphorylation of the beta-adrenergic receptor. Proc Natl Acad Sci USA. 1983;80(11):3173-3177.

37. Kühn H, Dreuer WJ. Light-dependent phosphorylation of rhodopsin by ATP. FEBS Lett. 1972;20(1):1-6.

38. Witzany G. Life: The Communicative Structure. Nordic Journal of Philosophy. 2000;3(1):155-162.

39. Sugden D, Davidson K, Hough KA, et al. Melatonin, Melatonin Receptors and Melanophores: A Moving Story. Pigment Cell Res. 2004;17(5):454-460.

40. Carpenter G, Cohen S. Epidermal growth factor. J Biol Chem 1990;265(14):7709-7712.

41. Roy AK, Chatterjee B. Crit Rev Eukaryot Gene Expr. 1995;5(2):157176.

42. Wiesmann C, de Vos AM. Nerve growth factor: structure and function. Cell Mol Life Sci. 2001;58 (5-6):748-759.
43. Goldstein A. Opioid peptides endorphins in pituitary and brain. Science. 1976;193(4258):1081-1086.

44. Kistler J, Stroud RM, Klymkowsky MW, et al. Biophys J. 1982;37(1):371383

45. Missale C, Nash SR, Robinson SW, et al. Dopamine receptors: from structure to function. Physiol Rev. 1998;78(1):189-225.

46. Kroeze WK, Kristiansen K, Roth BL. Molecular biology of serotonin receptors structure and function at the molecular level. Curr Top Med Chem. 2002;2(6):507-528.

47. Schroder K, Hertzog PJ, Ravasi T, et al. Interferon-gamma:an overview of signals, mechanisms and functions. J Leukoc Biol. 2004;75(2):163189

48. Chung CW, Cooke RM, Amanda EIP, et al. The Three-Dimensional Solution Structure of RANTES. Biochemistry. 1995;34(29):9307-9314.

49. Small KM, McGraw DW, Liggett SB. Pharmacology and physiology of human adrenergic receptor polymorphisms. Annu Rev Pharmacol Toxicol. 2003;43:381-411.

50. Adams TE, Epa VC, Garrett TP, et al. Cell Mol Life Sci. 2000;57(7):1050 1093.

51. Ross EM, Gilman AG. Biochemical properties of hormone sensitive adenylate cyclase. Annu Rev Biochem. 1980;49:533-564.

52. Fung B, Stryer L. Photolyzed rhodopsin catalyses the exchange of GTP for bound GDP in retinal rod outer segments. Proc Natl Acad Sci USA. 1980;77(5):2500-2504

53. Pedersen SE, Ross EM. Functional reconstitution of beta-adrenergic receptors and the stimulatory GTP-binding protein of adelnylate cyclase. Proc Natl Acad Sci USA. 1982;79(23):7228-7232.

54. Rubenstein LA, Lanzara RG. Journal of Molecular Structure (Theochem). 1998;430:57-71.

55. Duchene J, Schanstra JP, Pecher C, et al. J Biol Chem. 2002;277(43):40375-40383.

56. Insel PA, Tang CM, Hahntow I, et al. Impact of GPCRs in clinical medicine: monogenic diseases, genetic variants and drug targets. Biochim Biophys Acta. 2007;1768(994):994-1005.

57. Schöneberg T, Schulz A, Biebermann H, et al. Mutant G-proteincoupled receptors as a cause of human diseases. Pharmacol Therap. 2004;104(3):173-206.

58. Morris $\mathrm{MB}$, Dastmalchi S, Church BW. Int J Biochem Cell Biol. $2009 ; 41: 721$

59. Tao Y. Pharmacol Therap. 2008;120:129.

60. Hartong DT, Berson EL, Dryja TP. Retinitis pigmentosa. Lancet 2006;368(9549):1795-1809.

61. Thompson MD, Burnham WM, Cole DE. The G protein-coupled receptors: pharmacogenetics and disease. Crit Rev Clin Lab Sci. 2005;42(4):311-392.

62. Benovic JL, Kühn H, Weyand I, et al. Functional desensitization of the isolated beta-adrenergic receptor by the beta-adrenergic receptor kinase:potential role of an analog of the retinal protein arrestin $(48 \mathrm{kDa}$ protein). Proc Natl Acad Sci USA. 1987;84(24):8879-8882.

63. Von Zastrow M, Kobilka BK. Antagonist-dependent and-independent steps in the mechanism of adrenergic receptor internalization. $J$ Biol Chem. 1994;269(28):18448-18452.

64. Hein L, Ishii K, Coughlin SR, et al. Intracellular targeting and trafficking of thrombin receptors. A novel mechanism för resensitization of G-protein coupled receptors. J Biol Chem. 1994;269(44):27719-27726. 
65. Caron MG, Srinivasan Y, Pitha J, et al. Affinity chromatography of the beta-adrenergic receptor. J Biol Chem. 1979;254(8):2923-2927.

66. Vauquelin G, Geynet P, Hanoune J, et al. Affinity chromatography of the beta-adrenergic receptor from turkey erythrocytes. Eur J Biochem. 1979;98:543-546.

67. Shorr RG, Lefkowitz RJ, Caron MG. Purification of the beta-adrenergic receptor. Identification of the hormone bining subunit. J Biol Chem. 1981;256(11):5820-5826.
68. Shorr RG, Heald SL, Jeffs PW, et al. The beta adrenergic receptor: rapid purification and covalent labeling by photoaffinity crosslinking. Proc Natl Acad Sci USA. 1982;79(9):2778-2782.

69. Benovic JL, Shorr RG, Caron MG, et al. The mammalian beta 2 adrenergic receptor: purification and characterization. Biochemistry. 1984;23(20):4510-4518. 